\title{
SR-PSOX/CXCL16 plays a critical role in the progression of colonic inflammation.
}

\section{$\operatorname{AUTHOR}(S):$}

Uza, Norimitsu; Nakase, Hiroshi; Yamamoto, Shuji; Yoshino, Takuya; Takeda, Yasuhiro; Ueno, Satoru; Inoue, Satoko; ... Yonehara, Shin; Ikeuchi, Hiroki; Chiba, Tsutomu

\section{CITATION:}

Uza, Norimitsu ...[et al]. SR-PSOX/CXCL16 plays a critical role in the progression of colonic inflammation.. Gut 2011, 60(11): 1494-1505

\section{ISSUE DATE:}

2011-11

URL:

http://hdl.handle.net/2433/149206

RIGHT:

(C) 2011 BM J Publishing Group Ltd \& British Society of Gastroenterology. 


\title{
SR-PSOX/CXCL16 plays a critical role in the progression of colonic inflammation
}

\author{
Norimitsu Uza, ${ }^{1}$ Hiroshi Nakase, ${ }^{1}$ Shuji Yamamoto, ${ }^{1}$ Takuya Yoshino, ${ }^{1}$ \\ Yasuhiro Takeda, ${ }^{1}$ Satoru Ueno, ${ }^{1}$ Satoko Inoue, ${ }^{1}$ Sakae Mikami, ${ }^{1}$ Minoru Matsuura, \\ Takeshi Shimaoka, ${ }^{2}$ Noriaki Kume, ${ }^{3}$ Manabu Minami, ${ }^{3}$ Shin Yonehara, ${ }^{4}$ Hiroki Ikeuchi, \\ Tsutomu Chiba ${ }^{1}$
}

\begin{abstract}
- An additional figure is published online only. To view this file please visit the journal online (http://gut.bmj.com).

${ }^{1}$ Department of Gastroenterology and Hepatology, Graduate School of Medicine, Kyoto University,

Kyoto, Japan

${ }^{2}$ Department of Molecular Preventive Medicine, Graduate School of Medicine, University of Tokyo, Tokyo, Japan

${ }^{3}$ Department of Cardiovascular Medicine, Graduate School of Medicine, Kyoto University, Kyoto, Japan

${ }^{4}$ Department of Animal Development and Physiology. Graduate School of Biostudies, Kyoto University, Kyoto, Japan ${ }^{5}$ Department of Surgery, Hyogo College of Medicine, Hyogo, Japan
\end{abstract}

\section{Correspondence to}

Professor Hiroshi Nakase, Department of Gastroenterology and Hepatology, Graduate School of Medicine, Kyoto University, 54

Shogoin-Kawara-cho, Sakyo-ku, Kyoto 606-8507, Japan;

hiropy@kuhp.kyoto-u.ac.jp

Revised 31 January 2011 Accepted 12 February 2011

Published Online First

6 April 2011

\section{ABSTRACT \\ Background and aims Inflammatory bowel disease (IBD)} is initiated and perpetuated by a dysregulated immune response to unknown environmental antigens such as luminal bacteria in genetically susceptible hosts. SR-PSOX/CXCL16, a scavenger receptor that binds phosphatidylserine and oxidised lipoprotein, has both phagocytic activity and chemotactic properties. The aim of this study was to investigate the role of SR-PSOX/CXCL16 in patients with IBD and experimental murine colitis.

Methods The serum levels of SR-PSOX/CXCL16 were measured in patients with IBD. The roles of SR-PSOX/ CXCL16 in phagocytosis of bacterial components and cytokine production by macrophages from wild-type (WT) and SR-PSOX/CXCL16 knockout (KO) mice were assessed. Colitis was induced by administering dextran sulfate sodium (DSS) to WT and SR-PSOX/CXCL16 KO mice. Colonic inflammation was analysed by clinical, histological and immunological parameters. Finally, the effect of a monoclonal antibody (mAb) to SR-PSOX/ CXCL16 on DSS-induced colitis and trinitrobenzene sulfonic acid-induced colitis models was evaluated Results Serum levels of SR-PSOX/CXCL16 correlated significantly with the disease activity of patients with IBD. Ex vivo experiments showed that SR-PSOX/CXCL16 was involved in both phagocytosis of bacterial antigens and the $T$ helper 1 immune response through the production of interleukin 12 and interferon $\gamma$. In vivo murine experiments demonstrated the upregulated gene expression of SR-PSOX/CXCL16 in inflamed colonic tissues and the predominant expression of SR-PSOX/ CXCL16 on macrophages. SR-PSOX/CXCL16 KO mice were less susceptible to colonic inflammation than were their WT littermates. Administration of SR-PSOX/CXCL16 $\mathrm{mAb}$ ameliorated the condition in the two different experimental colitis models.

Conclusions SR-PSOX/CXCL16 plays a critical role in colonic inflammation and could be a potential therapeutic target for patients with IBD.

\section{INTRODUCTION}

Inflammatory bowel diseases (IBDs), including Crohn's disease (CD) and ulcerative colitis (UC), are chronic and relapsing-remitting conditions with unknown aetiology. Previous clinical and basic observations suggest that inflammation is initiated and perpetuated by a dysregulated immune response to unknown environmental antigens such as luminal bacteria in genetically susceptible hosts. ${ }^{1}$ Recent genome-wide association studies showed

\section{Significance of this study}

What is already known about this subject?

- Inflammatory bowel disease (IBD) is associated with a dysregulated immune response to unknown environmental antigens including luminal bacteria in genetically susceptible hosts.

- SR-PSOX/CXCL16 is associated with several inflammatory diseases.

- SR-PSOX/CXCL16 is constitutively expressed in the small intestine but not in normal colonic tissues.

- SR-PSOX/CXCL16 has two different biological activities: as a scavenger receptor and as a chemokine.

What are the new findings?

- Serum levels of SR-PSOX/CXCL16 correlated with the disease activity of IBD.

- SR-PSOX/CXCL16 expression is upregulated in inflamed colonic tissues and predominantly detected on macrophages.

- SR-PSOX/CXCL16 is involved in not only phagocytosis of bacterial antigens but also the $\mathrm{T}$ helper 1 immune response in the progression of colitis.

- SR-PSOX/CXCL16 monoclonal antibody ameliorated the condition in two different experimental colitis models.

How might it impact on clinical practice in the foreseeable future?

- Our data provide the first evidence for a critical role for SR-PSOX/CXCL16 in the progression of colonic inflammation ex vivo and in vivo. These data suggest that SR-PSOX/CXCL16 could be a potential therapeutic target for patients with IBD.

that genes involved in both innate and adaptive immune responses could be risk factors for developing IBD. ${ }^{2}{ }^{3}$ Moreover, an abnormal response of intestinal macrophages to commensal bacteria was reported to result in chronic intestinal inflammation. ${ }^{4}$ Therefore, it is important to investigate the relationship between luminal bacteria and antigenpresenting cells (APCs) in the pathogenesis of IBD Indeed, we showed that macrophage-targeting treatment ameliorates colonic inflammation in an experimental colitis model. ${ }^{5}$ Thus, the control of 
molecules related to macrophages appears to be a promising approach for the treatment of IBD.

Chemokines are a superfamily of small chemotactic cytokines and are classified into four major subfamilies on the basis of the motif of the first two cysteine residues: CC, CXC, C and CX3C subfamilies. ${ }^{6}$ The most important function of chemokines is the ability to regulate leucocyte trafficking and retention in lymphoid tissues and in peripheral tissues in both homeostasis and inflammation. ${ }^{7} 8$ The expression of several chemokines increases in the colonic tissues of both experimental murine colitis models and patients with IBD, ${ }^{9} 10$ and these chemokines are suggested to play a role in the pathophysiology of colitis.

SR-PSOX/CXCL16, a scavenger receptor that binds phosphatidylserine and oxidised lipoprotein, is a chemokine of the CXC family and has been identified as a novel transmembrane protein. ${ }^{11-13}$ In the static state, SR-PSOX/CXCL16 is expressed in various lymphoid tissues including the thymus, spleen, lymph nodes and Peyer's patches, and in non-lymphoid tissues including the lung, liver, kidney and small intestine, but not colonic tissue. ${ }^{11}{ }^{12}$ Among immune cells, SR-PSOX/CXCL16 is found primarily on the surface of APCs such as monocytes/ macrophages and dendritic cells. ${ }^{11-13}$ SR-PSOX/CXCL16 has two different biological activities: as a scavenger receptor that mediates adhesion and phagocytosis of both Gram-positive and Gram-negative bacteria by $\mathrm{APCs}^{14}$ and as a chemokine for CXCR6-expressing cells such as naïve CD8 T cells, T helper 1 (Th1)-polarised CD4 and CD8 T cells, and natural killer T cells. Accordingly, it is possible that SR-PSOX/CXCL16 plays an important role in both innate and adaptive immunity by mediating the uptake of bacteria as well as the recruitment of CXCR6-expressing $\mathrm{T}$ cells by APCs. Although SR-PSOX/ CXCL16 has been shown to be involved in several inflammatory conditions, ${ }^{15-17}$ little is known about the function of SR-PSOX/ CXCL16 in intestinal inflammation.

The aim of this study was to elucidate the role of SR-PSOX/ CXCL16 in the pathophysiology of IBD. We first measured the serum levels of SR-PSOX/CXCL16 in patients with IBD. We assessed the role of SR-PSOX/CXCL16 in phagocytosis of bacterial components and cytokine production by macrophages in SR-PSOX/CXCL16 knockout (KO) mice. Next, we investigated the role of SR-PSOX/CXCL16 in a dextran sulfate sodium (DSS)-induced colitis model. Finally, we examined the effects of a monoclonal antibody ( $\mathrm{mAb}$ ) to SR-PSOX/CXCL16 in two experimental murine colitis models: DSS-induced colitis and 2,4,6-trinitrobenzene sulfonic acid (TNBS)-induced colitis.

\section{MATERIALS AND METHODS \\ Human serum samples}

Human serum samples were obtained from 14 patients (11 men and 3 women; mean age, 27.8 26.4 years) with active CD, 16 patients ( 9 men and 7 women; $27.7 \pm 7.4$ years) with inactive CD, 16 patients ( 10 men and 6 women; $27.2 \pm 15.6$ years) with active UC, 13 patients ( 10 men and 3 women; $29.5 \pm 14.8$ years) with inactive UC and 16 healthy volunteers (15 men and 1 woman; $34.6 \pm 3.1$ years). The clinical characteristics of patients with CD and UC are shown in table 1 . The disease activity of the patients with CD and UC was determined according to the Crohn's Disease Activity Index $(\mathrm{CDAI})^{18}$ and the Clinical Activity Index (CAI), ${ }^{19}$ respectively. A CDAI $\geq 150$ and a CAI $\geq 5$ was defined as active CD and active UC, respectively. ${ }^{20} 21$ Informed consent was obtained from all patients and volunteers, and the experimental design using these samples was approved by the Kyoto University Hospital Ethics Committee.
Table 1 Clinical characteristics of patients

\begin{tabular}{|c|c|c|}
\hline (A) Patients with CD & Active CD $(n=14)$ & Inactive CD $(n=16)$ \\
\hline Age (years) & $27.8 \pm 6.4$ & $27.7 \pm 7.4$ \\
\hline Gender (M/F) & $11 / 3$ & $9 / 7$ \\
\hline Disease duration (years) & $8.0 \pm 7.3$ & $8.3 \pm 7.3$ \\
\hline \multirow[t]{3}{*}{ Disease location (n) } & Ileal only (3) & Ileal only (8) \\
\hline & Ileocolonic (7) & Ileocolonic (4) \\
\hline & Colonic only (4) & Colonic only (4) \\
\hline CDAI & $248.0 \pm 87$ & $110.1 \pm 25.8^{*}$ \\
\hline (B) Patients with UC & Active UC $(n=16)$ & Inactive UC $(n=13)$ \\
\hline Age (years) & $27.2 \pm 15.6$ & $29.5 \pm 14.8$ \\
\hline Gender (M/F) & $10 / 6$ & $10 / 3$ \\
\hline Disease duration (years) & $2.1 \pm 1.8$ & $9.1 \pm 4.8^{*}$ \\
\hline \multirow[t]{3}{*}{ Disease location (n) } & Pancolitis (9) & Pancolitis (7) \\
\hline & Left-sided colitis (7) & Left-sided colitis (5) \\
\hline & Proctitis (0) & Proctitis (1) \\
\hline CAI & $10.9 \pm 2.9$ & $1.2 \pm 1.2^{*}$ \\
\hline
\end{tabular}

The values are expressed as mean $\pm S D$ or number of patients.

${ }^{*} \mathrm{p}<0.01$ between active and inactive $\mathrm{CD}$ or UC.

CAl, Clinical Activity Index; CD, Crohn's disease; CDAl, Crohn's Disease Activity Index; $\mathrm{F}$, female; M, male, UC, ulcerative colitis.

\section{Mice}

SR-PSOX/CXCL16 KO mice were generated in collaboration with Sankyo Co. (Tokyo, Japan) as described previously. ${ }^{22}$ Heterozygous mice were generated by crossing SR-PSOX/ CXCL16 KO mice and C57BL/6 mice, and were intercrossed to obtain homozygous SR-PSOX/CXCL16 KO and wild-type (WT) littermates. The genotyping of $\mathrm{F}_{2}$ mice was performed by PCR at least twice using the following primers: 5 '-TACCGCAGGGTACTTTGGATCA-3' and 5'-TTGCGCTCAAAGCAGTCCACTA-3' for detection of the WT SR-PSOX/CXCL16 allele (351 bp), and $5^{\prime}$-GGATCTCCTGTCATCTCACCTTGC-3' and 5'-CGGCCACAGTCGATGAATCCAGAA-3' for detection of the KO allele (333 bp). SR-PSOX/CXCL16 KO mice and their WT littermates from intercrosses of heterozygous mice were used in the experiments. C57BL/6 mice and SJL/J mice were purchased from Japan SLC (Shizuoka, Japan) and Charles River Japan (Kanagawa, Japan), respectively. All mice were fed with standard laboratory chow and water ad libitum, and housed in specific pathogen-free conditions in the animal facility of Kyoto University. All experiments were performed with female mice at 8-12 weeks of age according to the protocol approved by the Animal Protection Committee of our institution.

\section{Preparation of thioglycollate-elicited peritoneal macrophages}

SR-PSOX/CXCL16 KO and WT mice were injected intraperitoneally with $3 \mathrm{ml}$ of $3 \%$ thioglycollate (Eiken Chemical Co., Tokyo, Japan) and peritoneal exudate cells (PECs) were harvested 4 days later. Cells were cultured with complete RPMI medium (RPMI 1640 medium (Gibco BRL, Eggenstein, Germany) supplemented with $10 \%$ heat-inactivated fetal bovine serum, $100 \mu \mathrm{g} / \mathrm{ml}$ streptomycin (Sigma Chemical Co., St Louis, Missouri, USA) and $100 \mu \mathrm{g} / \mathrm{ml}$ penicillin (Sigma Chemical Co.)) for $2 \mathrm{~h}$ and, after removal of non-adherent cells, adherent PECs were cultured as peritoneal macrophages. Adherent PECs were resuspended and adjusted to a concentration of $1 \times 10^{6} \mathrm{cells} / \mathrm{ml}$.

\section{Preparation of caecal bacterial lysates (CBLs)}

CBLs were prepared directly from the caecal contents of SR-PSOX/CXCL16 KO and WT mice according to a protocol described by Cong et al. ${ }^{23}$ The sterility of the lysates was confirmed by culture. 


\section{Phagocytosis assay}

The ex vivo phagocytosis assay was performed using pHrodo Escherichia coli BioParticles conjugate for phagocytosis (Invitrogen) according to the manufacturer's instructions. The fluorescence intensity was measured using a microplate reader (Fluoroskan Ascent FL: Labsystems, Helsinki, Finland) at the indicated times. For fluorescence microscopic observation of phagocytosis, peritoneal macrophages were seeded at $3 \times 10^{5}$ cells/well in 8-well Lab-Tek chamber glass slides (NUNC Roskilde, Denmark) and incubated overnight in complete medium. The wells were washed with phosphate-buffered saline (PBS), fluorescent particles were added and the slides were observed using fluorescence microscopy (Olympus, Tokyo, Japan) at the indicated times.

\section{Stimulation and cytokine production assay of peritoneal macrophages}

Peritoneal macrophages were seeded at $2.5 \times 10^{5}$ cells/well in 48well culture plates and incubated overnight in complete medium. Cells were primed with $500 \mathrm{U} / \mathrm{ml}$ interferon $\gamma$ (IFN $\gamma$; R\&D Systems, Minneapolis, Minnesota, USA) for $16 \mathrm{~h}$ and then stimulated with $100 \mathrm{ng} / \mathrm{ml}$ lipopolysaccharide (LPS (L5668-2ML); Sigma Chemical Co.) or $30 \mu \mathrm{g} / \mathrm{ml} \mathrm{CBL}$ for $24 \mathrm{~h}$. The supernatants were collected and subjected to analysis of cytokine production by ELISA.

\section{Induction of experimental colitis}

DSS-colitis was induced in SR-PSOX/CXCL16 KO mice, WT littermates and $\mathrm{C} 57 \mathrm{BL} / 6$ mice using a modification of the method described by Inoue et al. ${ }^{24}$ In brief, to induce colitis, 3\% DSS (molecular mass, 36-50 kDa; MP Biomedicals, Solon, Ohio, USA) in regular drinking water was administered for 5 days (from day 0 to 4 ), and then regular drinking water was given from day 5. Normal control mice received regular drinking water throughout the experiment. The mice were sacrificed on day 8 or day 14 to evaluate the acute inflammatory phase or the restitution phase, respectively. TNBS-colitis was induced in SJL/J mice using a modification of the method described by Neurath et al. ${ }^{25}$

\section{The neutralising effect of $\mathrm{mAb}$ to SR-PSOX/CXCL16 on colitis models}

To investigate the effect of blocking SR-PSOX/CXCL16 on experimental colitis, C57BL/6 mice with DSS-induced colitis and $\mathrm{SJL} / \mathrm{J}$ mice with TNBS-induced colitis were injected intraperitoneally with $500 \mu \mathrm{g}$ of $\mathrm{mAb}$ to SR-PSOX/CXCL16 ${ }^{26}$ dissolved in $200 \mu \mathrm{l}$ of PBS or an equal amount of control rat immunoglobulin G (IgG) (MP Biomedicals) in PBS once a day from days 1 to 7 and days 1 to 3 , respectively.

\section{Microscopic assessment of colitis}

The colonic tissues were treated using the same method as in Matsuura et $a l^{27}$ and then analysed histologically in a blind manner. Histological damage of DSS- and TNBS-induced colitis was quantified using the histological scoring system described by Williams et al ${ }^{28}$ and Elson et al, ${ }^{29}$ respectively.

\section{Colon fragment culture}

Fragment culture of distal colon segments was performed according to the published method. ${ }^{30}$ Culture supernatants were collected and stored at $-80^{\circ} \mathrm{C}$ until assayed.

Isolation and stimulation of mesenteric lymph node (MLN) cells MLNs were isolated as described previously. ${ }^{31}$ MLN cells $\left(2 \times 10^{5}\right.$ cells/well) were incubated with immobilised anti-CD3 $(5 \mu \mathrm{g} / \mathrm{ml}$ antimouse CD3e; BD Pharmingen, San Diego, California, USA) plus CD28 (2 $\mu \mathrm{g} / \mathrm{ml}$ antimouse CD28, BD Pharmingen) in $200 \mu \mathrm{l}$ of complete medium containing $5 \times 10^{-5} \mathrm{M} 2$-mercaptoethanol (Sigma Chemical Co.) in a $5 \% \mathrm{CO}_{2}$ incubator at $37^{\circ} \mathrm{C}$ for $72 \mathrm{~h}$. The supernatant of the culture medium was collected and stored at $-80^{\circ} \mathrm{C}$ until assayed.

\section{Isolation of colonic lamina propria macrophages}

Lamina propria macrophages were isolated using a modified protocol as described previously. ${ }^{4}$ Briefly, mice were sacrificed, and colonic tissues were removed, washed with cold PBS and cut into three pieces. The resected colonic tissues were shaken with Hanks' balanced salt solution (HBSS; Gibco) for $1 \mathrm{~min}$ at 2800 rpm in a Mini Bead Beater (Biospec Products, Bartlesville, Oklahoma, USA) to remove faeces and mucus, dissected into small pieces and then incubated with HBSS containing $5 \%$ fetal calf serum and $5 \mathrm{mM}$ EDTA (Gibco) for $30 \mathrm{~min}$ at $37^{\circ} \mathrm{C}$ under rotation at $120 \mathrm{rpm}$. After washing, the pieces were incubated with complete RPMI medium containing $1 \mathrm{mg} / \mathrm{ml}$ collagenase type II (Invitrogen, Carlsbad, California, USA), $1 \mathrm{mg} / \mathrm{ml}$ dispase (Gibco) and $40 \mu \mathrm{g} / \mathrm{ml}$ DNase (Roche, Mannheim, Germany) for $60 \mathrm{~min}$ at $37^{\circ} \mathrm{C}$ under rotation at $120 \mathrm{rpm}$ to digest colonic tissues. After washing, the extracted cells were filtered and subjected to a magnetic cell separation system (Miltenyi Biotec, Auburn, California, USA) with antimouse CD11b microbeads to separate colonic lamina propria macrophages. Cell viability was determined by trypan blue staining, and $>95 \%$ purity was confirmed by flow cytometry.

\section{ELISA}

The serum level of SR-PSOX/CXCL16 in the human subjects was determined quantitatively using a human CXCL16 immunoassay ELISA kit (R\&D Systems). In the mouse model, the levels of SR-PSOX/CXCL16 in the serum and the supernatant of the colon fragment culture were measured using a mouse CXCL16 ELISA kit (R\&D Systems). The cytokine levels of interleukin 6 (IL-6) and IL-12/23 p40 in the supernatants of the culture medium of thioglycollate-elicited peritoneal macrophage were measured using mouse ELISA kits (eBioscience, San Diego, California, USA). The secretions of IFN $\gamma$ and IL-17 into the supernatants of culture medium in activated MLN cells were determined by mouse ELISA kits (eBioscience).

\section{Quantitative analysis of gene expression of SR-PSOX/CXCL16 in colonic tissue}

mRNA was assessed using colonic tissues isolated from the distal colon of WT mice with or without DSS-induced colitis. The extraction of total RNA, generation of cDNA and real-time reverse transcription-PCR (RT-PCR) were performed as described previously. ${ }^{31}$ The following primers were used: SR-PSOX/CXCL16, 5'-GGCTTTGGACCCTTGTCTCTTG-3' (forward) and 5'-TTGCGCTCAAAGCAGTCCACT-3' (reverse); and glyceraldehyde phosphate dehydrogenase (GAPDH), 5'-CAA CTTTGTCAAGCTCATTTCC-3' (forward) and 5'-GGTCCAG GGTTTCTTACTCC-3' (reverse).

\section{Western blot analysis}

Colonic tissues were lysed in RIPA buffer (1\% Triton X-100, $0.5 \%$ Na-deoxycholate, $0.1 \%$ sodium dodecyl sulfate (SDS), $20 \mathrm{mmol} / \mathrm{l}$ Tris- $\mathrm{HCl}(\mathrm{pH} 7.4)$ ) with protease inhibitor cocktail (Sigma Chemical Co.), and the insoluble material was removed by centrifugation at $12000 \mathrm{~g}$ for $5 \mathrm{~min}$ at $4^{\circ} \mathrm{C}$. The supernatants were boiled in sample buffer $(0.05 \mathrm{~mol} / \mathrm{l}$ Tris- $\mathrm{HCl}, 2 \% \mathrm{SDS}, 6 \%$ $\beta$-mercaptoethanol, 10\% glycerol, 1.25\% bromophenol blue), 
subjected to SDS-PAGE (10\% polyacrylamide gels) and transferred onto polyvinylidine fluoride membranes (PALL Corporation, Pensacola, Florida, USA). The membranes were blocked with blocking buffer (Tris-buffered saline with $0.5 \%$ Tween-20 (TBS-T) containing 5\% milk powder) and then incubated with a 1:1000 dilution of anti-CXCL16 $\mathrm{mAb}$ and with 1:5000 dilution
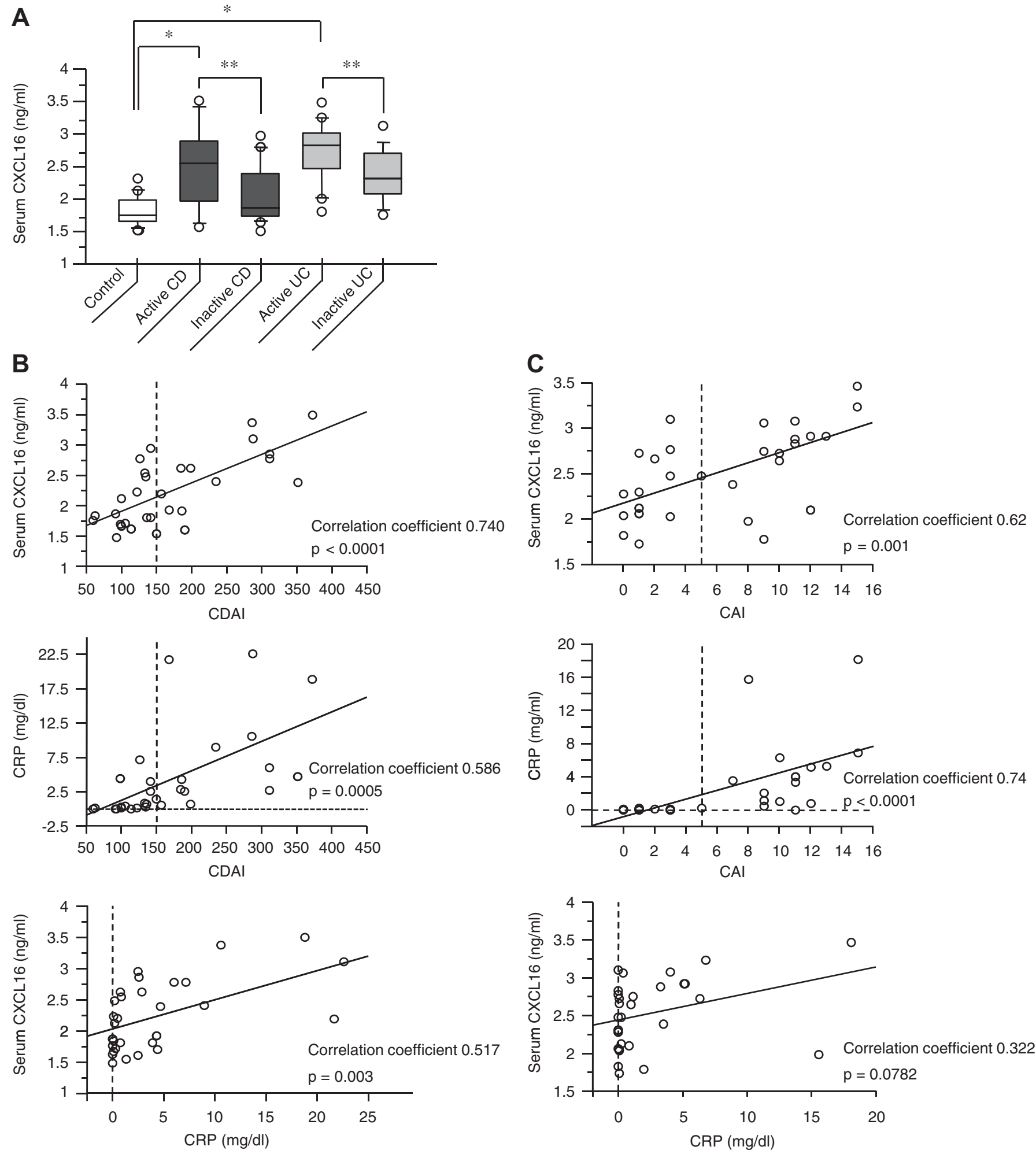

Figure 1 Serum levels of human SR-PSOX/CXCL16 are higher in patients with active inflammatory bowel disease (IBD). Serum samples were obtained from patients with active Crohn's diease (CD) $(n=14)$, inactive CD $(n=16)$, active ulcerative colitis (UC) ( $n=16)$ and inactive UC ( $n=13)$, and from healthy controls $(n=16)$. Results are expressed as means \pm SEM. ${ }^{*} p<0.05$ compared with control and ${ }^{*} p<0.05$ between patients with active IBD and inactive IBD. (A) The statistical difference of serum SR-PSOX/CXCL16 in patients with IBD and healthy controls was determined by unpaired Student $t$ test. (B) The relationship among serum SR-PSOX/CXCL16, C-reactive protein (CRP) and Crohn's Disease Activity Index (CDAI) in patients with CD was assessed by the Pearson correlation coefficient test. (C) The relationship among serum SR-PSOX/CXCL16, CRP and Clinical Activity Index (CAI) in patients with UC was investigated by the Pearson correlation coefficient test or Spearman correlation test. 
of anti- $\beta$-actin $\mathrm{mAb}$ (Sigma Chemical Co.) overnight at $4^{\circ} \mathrm{C}$. The membranes were washed and incubated with a horseradish peroxidase (HRP)-conjugated IgG. The immunoreactive bands were visualised with Immobilon Western chemiluminescent HRP substrate (Millipore, Billerica, Massachusetts, USA), and the images were recorded using a chemiluminescent image reader (LAS-3000; Fujifilm, Tokyo, Japan).

\section{Immunohistochemistry}

For SR-PSOX/CXCL16 immunostaining, colonic tissues of WT mice with or without DSS-induced colitis, and Peyer's patches as the positive control, were prepared as described previously. ${ }^{24}$ The sections were incubated with biotinylated anti-CXCL16 antibody (1:250; R\&D Systems) or goat IgG isotype control overnight at $4^{\circ} \mathrm{C}$. After washing, the sections were incubated with
Figure 2 SR-PSOX/CXCL16 plays a role in phagocytosis of bacterial components and the production of interleukin 12 (IL-12) by macrophages. Thioglycollate-elicited peritoneal macrophages from SR-PSOX/CXCL16 knockout (KO) and wild-type (WT) mice were subjected to an ex vivo phagocytosis assay against bacteria. (A) Microscopic observation of phagocytosis was performed in peritoneal macrophages from WT mice (upper column) and SR-PSOX/CXCL16 KO mice (lower column). The upper and lower panels of each column show light microscopic findings and fluorescent images, respectively. Scale bars, $25 \mu \mathrm{m}$. (B) Fluorescence intensity, from which the fluorescence values of the no-cell background control wells were subtracted, was measured using a microplate reader at the indicated times. The statistical comparison of fluorescence intensity between WT (open circles) and SR-PSOX/CXCL16 KO macrophages (filled circles) was assessed by repeated measure analysis of variance followed by unpaired Student $t$ test. (C) Peritoneal macrophages from WT (open bars) and SR-PSOX/CXCL16 KO mice (filled bars) were incubated with $500 \mathrm{U} / \mathrm{ml}$ interferon $\gamma$ (IFN $\gamma$ ) for $16 \mathrm{~h}$, followed by stimulation with $100 \mathrm{ng} / \mathrm{ml}$ lipopolysaccharide (LPS) or $30 \mu \mathrm{g}$ caecal bacterial lysate (CBL) for $24 \mathrm{~h}$, and the culture supernatants were analysed by ELISA to measure the concentrations of IL-6 and IL-12/23 p40. The results are expressed as means \pm SEM of the data from three independent experiments. The statistical difference was determined by unpaired Student $t$ test. ${ }^{*} p<0.05$ and ${ }^{* *} \mathrm{p}<0.01$ between SR-PSOX/ CXCL16 KO and WT macrophages.
A

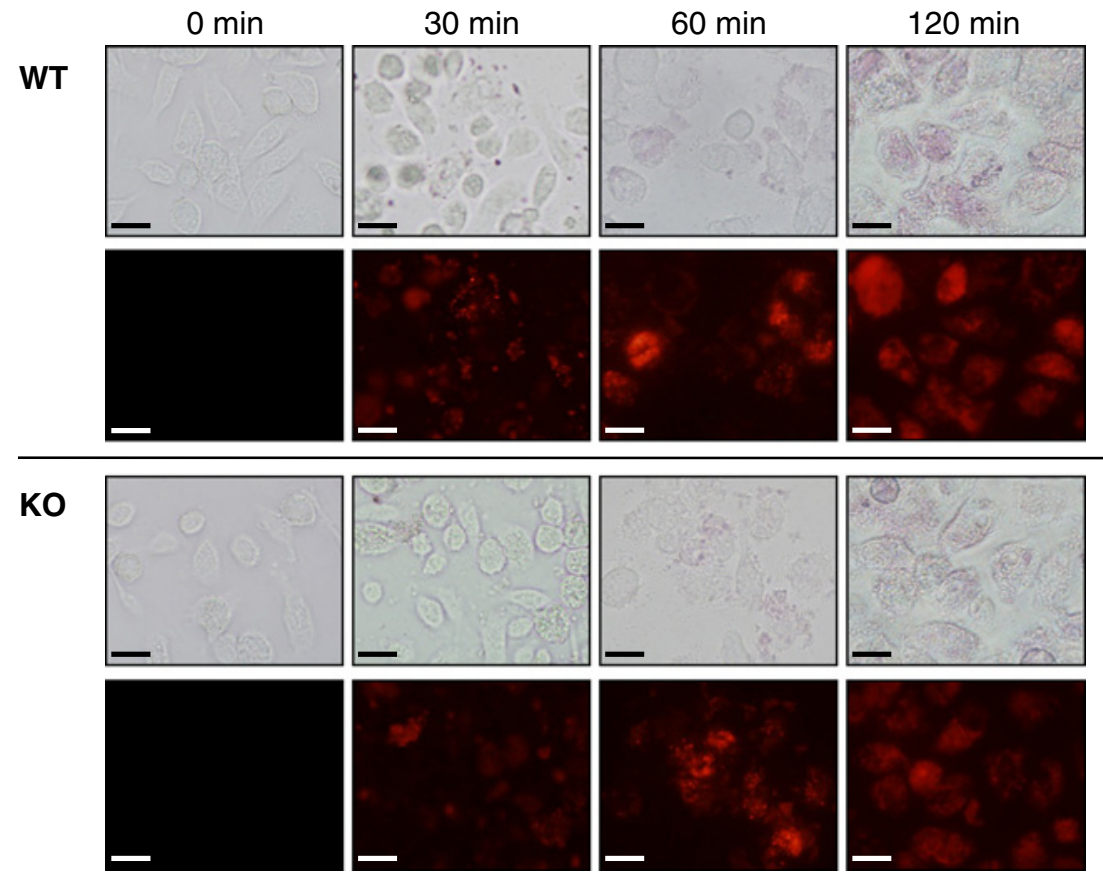

B

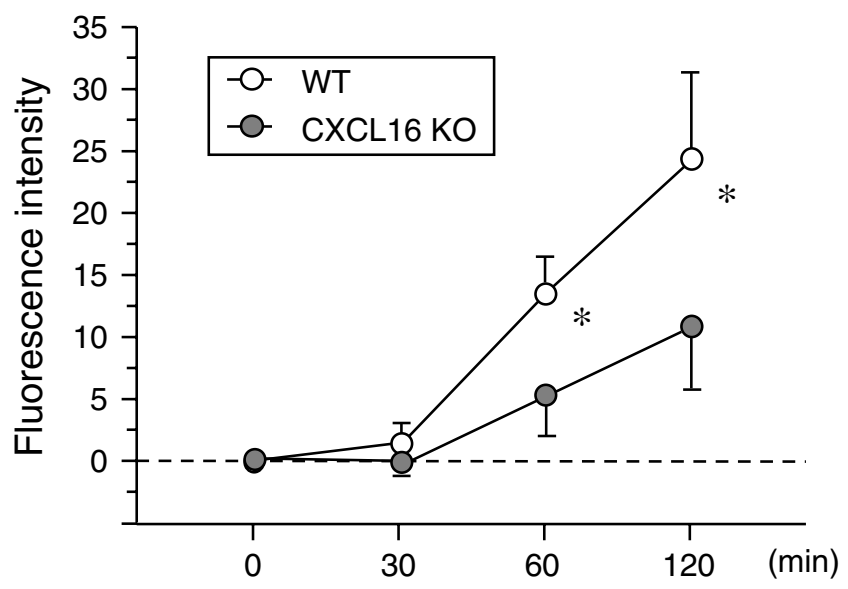

C

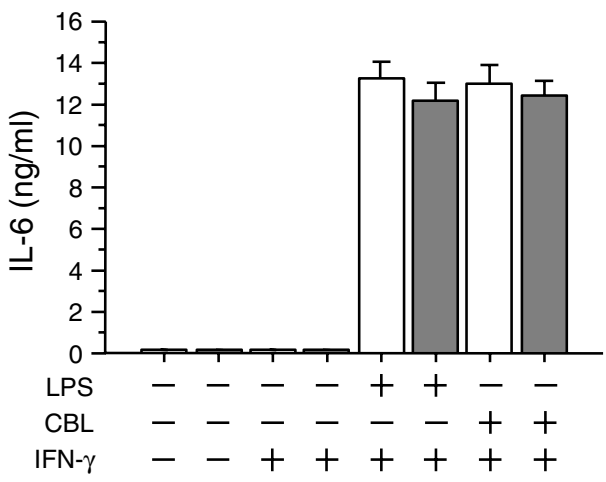


streptavidin-HRP (1:1000; PerkinElmer, Waltham, Massachusetts, USA), treated with a tyramide signal amplification (TSA) biotin system (PerkinElmer), visualised with 3, 3'-diaminobenzidine tetrahydrochloride and counterstained with haematoxylin solution (Wako Pure Chemical, Osaka, Japan).

For immunofluorescence co-staining, cryosections $(6 \mu \mathrm{m})$ of colonic tissue were fixed in cold acetone for $2 \mathrm{~min}$ and blocked with the Biotin Block system (DakoCytomation, Carpinteria, California, USA), Protein Block Serum-Free (DakoCytomation) and anti-CD16/32 mAb (1:500; eBioscience) to block endogenous biotin binding, non-specific protein binding and nonspecific Fc binding, respectively. The sections were incubated with fluorescein isothiocyanate (FITC)-conjugated anti-CD11b $\mathrm{mAb}$ (1:200; BD Pharmingen) and biotinylated anti-CXCL16 antibody (1:1000; R\&D Systems) or goat IgG isotype control overnight at $4^{\circ} \mathrm{C}$. After quenching, the sections were incubated with streptavidin-HRP (1:1000). The signals were enhanced using the TSA biotin system (PerkinElmer) according to the manufacturer's protocol and finally visualised by Alexa 594-conjugated streptavidin (1:2000; Invitrogen).

Furthermore, to evaluate the difference in cells recruited to colonic tissues of SR-PSOX/CXCL16 KO and WT mice with or without DSS-induced colitis, colonic tissues were incubated with FITC-conjugated CD3 (1:200), CD11b (1:100) and CD11c (1:100) (eBioscience), followed by nuclear counterstaining with 4 ,6-diamidino-2-phenylindole (DAPI; 1:10000). Mean numbers of cells recruited to colonic tissues from five different microscopic fields under high power $(\times 400)$ were calculated in each mouse, and means \pm SEM from six mice of each group are shown. Images were recorded using a fluorescence microscope (Olympus).

\section{Fluorescence in situ hybridisation (FISH)}

The universal eubacterial oligonucleotide probe EUB-338 (5'-GCT GCC TCC CGT AGG AGT-3') was synthesised and the $5^{\prime}$ end was labelled with carbocyanite dye (Cy5). The sections (4 $\mu \mathrm{m}$ thick) were deparaffinised and incubated with $50 \mathrm{ng}$ of oligonucleotide probe in $10 \mu \mathrm{l}$ of hybridisation buffer (containing $20 \%$ formamide, $0.9 \mathrm{M} \mathrm{NaCl}, 20 \mathrm{mM}$ Tris- $\mathrm{HCl}$ $(\mathrm{pH} 7.2), 0.01 \% \mathrm{SDS}$ ) in a humid chamber overnight at $46^{\circ} \mathrm{C}$. After washing with the same buffer, nuclear counterstaining was performed with DAPI $(0.04 \mu \mathrm{g} / \mathrm{ml})$. Slides were visualised by fluorescence microscopy with a Leica CW4000 system (Leica, Wetzlar, Germany).

\section{Statistical analysis}

All numerical data are expressed as means \pm SEM. The differences between groups were analysed by unpaired Student t test, Mann-Whitney U test and analysis of variance (ANOVA) for repeated measures. Parametric and non-parametric correlation was examined by the Pearson correlation coefficient test and the Spearman correlation test, respectively. The cumulative survival rate was calculated by the Kaplan-Meier method, and survival curves were compared by log-rank test. A p value $<0.05$ was considered significant.

\section{RESULTS \\ Serum levels of SR-PSOX/CXCL16 increase in patients with active IBD}

The serum levels of SR-PSOX/CXCL16 were significantly higher in patients with active $\mathrm{CD}$ and UC than in control subjects. The serum levels of SR-PSOX/CXCL16 were also significantly higher in patients with active $\mathrm{CD}$ and $\mathrm{UC}$ than in those with inactive $\mathrm{CD}$ and $\mathrm{UC}$, respectively (figure $1 \mathrm{~A}$ ). Also, the serum levels of SR-PSOX/CXCL16 significantly correlated with clinical activities of both CD and UC (CADI and CAI; figure 1B,C). Considering the relationship among SR-PSOX/CXCL16, C-reactive protein (CRP) and clinical activities in CD and UC, SR-PSOX/CXCL16 might be a more suitable marker reflecting the disease activity of CD compared with that of UC.

\section{SR-PSOX/CXCL16 plays a role in phagocytosis of bacterial components}

SR-PSOX/CXCL16 is reported to be a chemokine expressed specifically on APCs such as macrophages and dendritic cells. ${ }^{11-13}$ In particular, we focused on macrophages that play a critical role in the uptake of luminal antigens and examined the ability of macrophages from SR-PSOX/CXCL16 KO and WT mice to phagocytose bacteria ex vivo. Fluorescence microscopy showed that the uptake of $E$ coli by macrophages from both SR-PSOX/CXCL16 KO mice and WT mice increased in a timedependent manner (figure 2A). Measurement of fluorescence intensity revealed that the fluorescence value was significantly lower from 60 to $120 \mathrm{~min}$ in SR-PSOX/CXCL16 $\mathrm{KO}$ macrophages than in WT macrophages (figure $2 \mathrm{~B}$ ).

\section{SR-PSOX/CXCL16 is involved in the production of IL-12 by macrophages}

To compare cytokine production by macrophages between SR-PSOX/CXCL16 KO and WT mice, we measured the levels of IL- 6 and IL-12/23 p40 in the supernatant from macrophages of mice stimulated with LPS or CBL after pretreatment with IFN $\gamma$. There was no difference in the production of IL- 6 by macrophages between SR-PSOX/CXCL16 KO and WT mice. In contrast, the production of IL-12/23 p40 by macrophages was

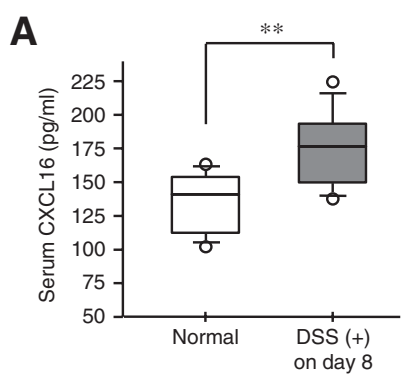

C

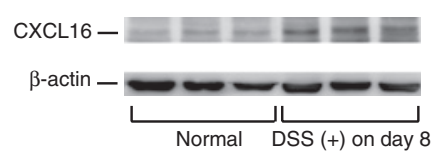

B

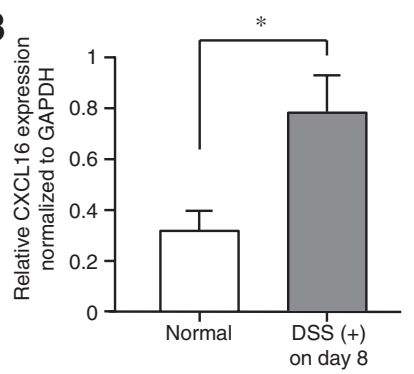

D

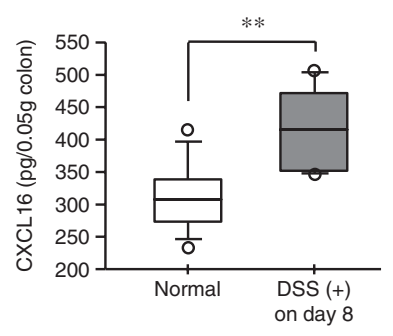

Figure 3 SR-PSOX/CXCL16 levels are higher in mice with dextran sulfate sodium (DSS)-induced colitis. (A) The serum levels of SR-PSOX/ CXCL16 in mice with DSS-induced colitis on day 8 and control mice were measured by ELISA. (B). The gene expression of SR-PSOX/CXCL16 in colonic tissues with or without DSS-induced colitis was determined by quantitative real-time reverse transcription-PCR (RT-PCR) and was normalised to glyceraldehyde phosphate dehydrogenase (GAPDH). (C). The production of SR-PSOX/CXCL16 in colonic tissues with or without DSS-induced colitis was investigated by western blot analysis. (D) SRPSOX/CXCL16 concentrations in supernatants of colon fragment cultures were measured by ELISA. The results are expressed as means \pm SEM $(n=10$ in each group). (A), (B) and (D) The statistical difference was determined by unpaired Student $t$ test. ${ }^{*} p<0.05$ and ${ }^{* *} p<0.01$ between mice with DSS-induced colitis and normal controls. 
significantly lower in SR-PSOX/CXCL16 KO mice than in WT mice (figure 2C). We also observed a significant difference in IL-12/23 p40 production by macrophages between SR-PSOX/ CXCL16 KO and WT mice even without pretreatment with IFN $\gamma$ (data not shown).

\section{Expression of SR-PSOX/CXCL16 increases in mice with DSS-induced colitis}

Next, we investigated the in vivo expression of SR-PSOX/ CXCL16 in the DSS-induced colitis model. The serum levels of SR-PSOX/CXCL16 were significantly higher in mice with DSS-induced colitis than in normal controls (figure 3A). To examine whether the expression of SR-PSOX/CXCL16 increases in inflamed tissues, we analysed the colonic tissues of mice with or without DSS-induced colitis. The gene expression of SR-PSOX/CXCL16 was significantly higher in colonic tissues of DSS-induced colitis than in normal colon (figure $3 \mathrm{~B}$ ). Western blot analysis and ELISA also revealed that SR-PSOX/CXCL16 expression was significantly higher in colonic tissues of DSS-induced colitis than in normal colon (figure 3C,D).
To identify the cells that mainly express SR-PSOX/CXCL16 in colonic tissues, we performed immunohistochemical analysis and immunofluorescent co-staining. The follicular-associated epithelia of Peyer's patches, used as a control, were positive for SP-PSOX/CXCL16, as reported previously (figure 4A, right upper panel). ${ }^{32}$ SR-PSOX/CXCL16-expressing cells were increased markedly in colonic tissues of mice with DSS-induced colitis compared with normal colons, and these cells were observed from the mucosae to the submucosa (figure 4A, right lower panel). Immunofluorescent images revealed that SR-PSOX/CXCL16expressing cells were mainly CD11b-positive cells (figure 4B).

\section{Activity of DSS-induced colitis is reduced in SR-PSOX/CXCL16 KO mice}

To investigate the role of SR-PSOX/CXCL16 in colonic inflammation, we compared SR-PSOX/CXCL16 KO and WT mice with DSS-induced colitis. Before the analysis, we confirmed that there was no difference in the subsets of lymphocytes between SR-PSOX/CXCL16 KO mice and WT mice in the static state (Supplementary figure 1 online). The amount of body weight
Figure 4 SR-PSOX/CXCL16 is expressed predominantly on macrophages in colonic tissues of mice with dextran sulfate sodium (DSS)-induced colitis. (A) Immunostaining was performed in Peyer's patches as a positive control, normal colons and colons with $3 \%$ DSS-induced colitis. Serial sections of each tissue were stained with $\mathrm{H \& E}$, control goat immunoglobulin $\mathrm{G}(\mathrm{IgG})$ and anti-mouse SR-PSOX/CXCL16 monoclonal antibody. (B). Immunofluorescent staining was performed in normal colons and colons with $3 \%$ DSS-induced colitis using antibodies against CD11b (green), SR-PSOX/CXCL16 (red) and control goat lgG. The merged images and their magnified images are shown. Scale bars, $50 \mu \mathrm{m}(A), 20 \mu \mathrm{m}$ (B, left 3 lanes) and $10 \mu \mathrm{m}(\mathrm{B}$, right lane).
A $H \& E$

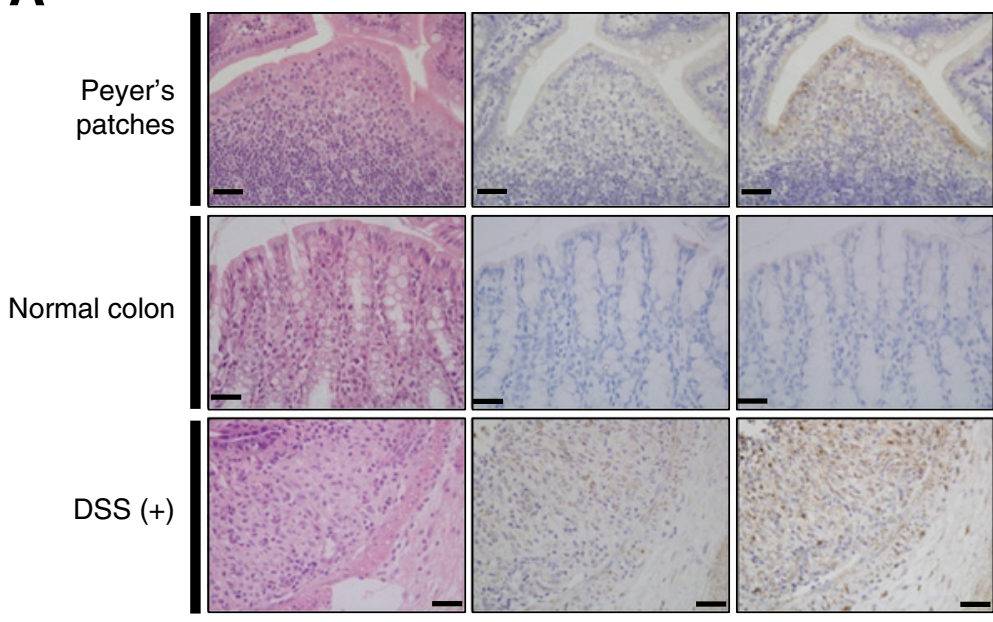

B

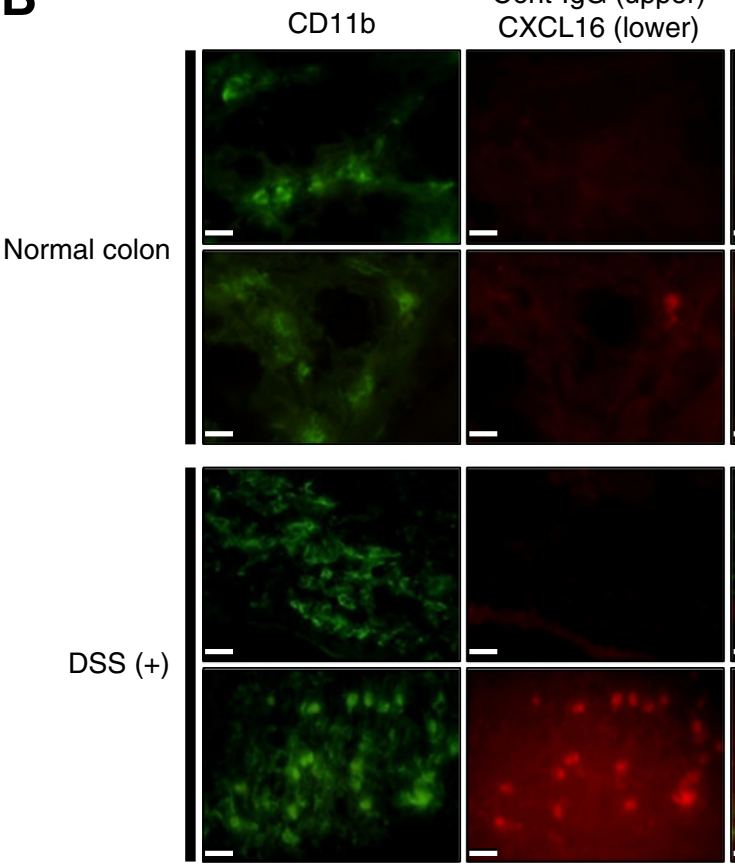

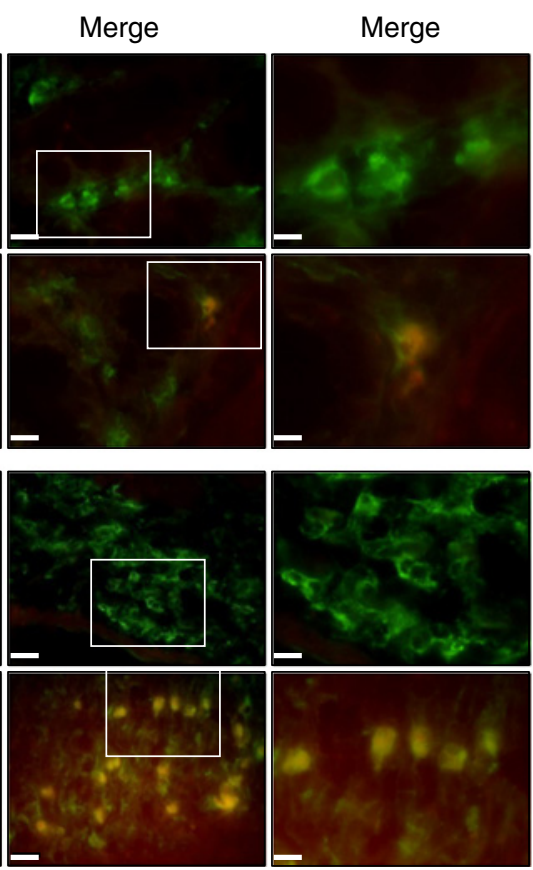




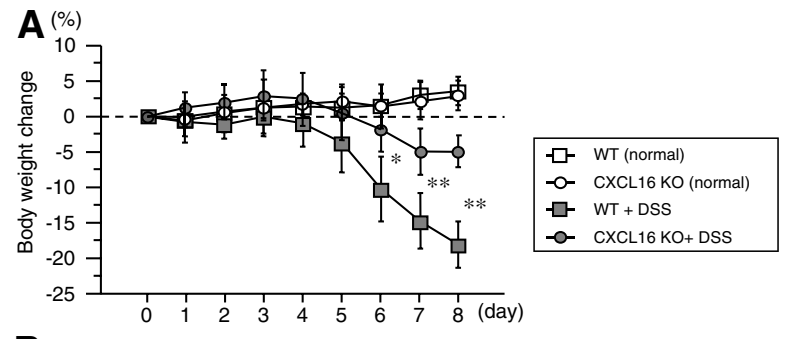

B
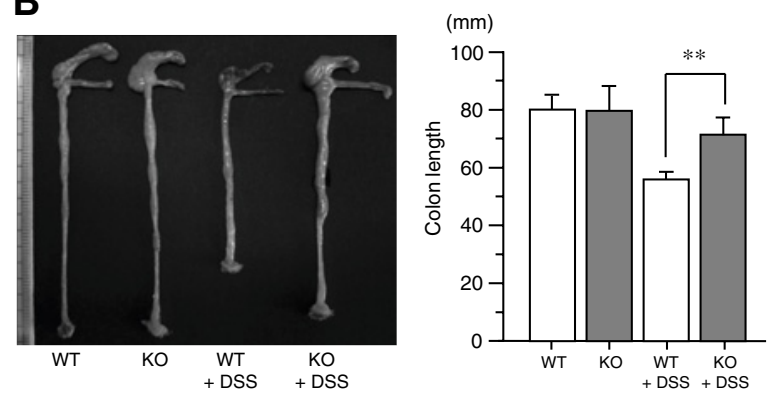

C
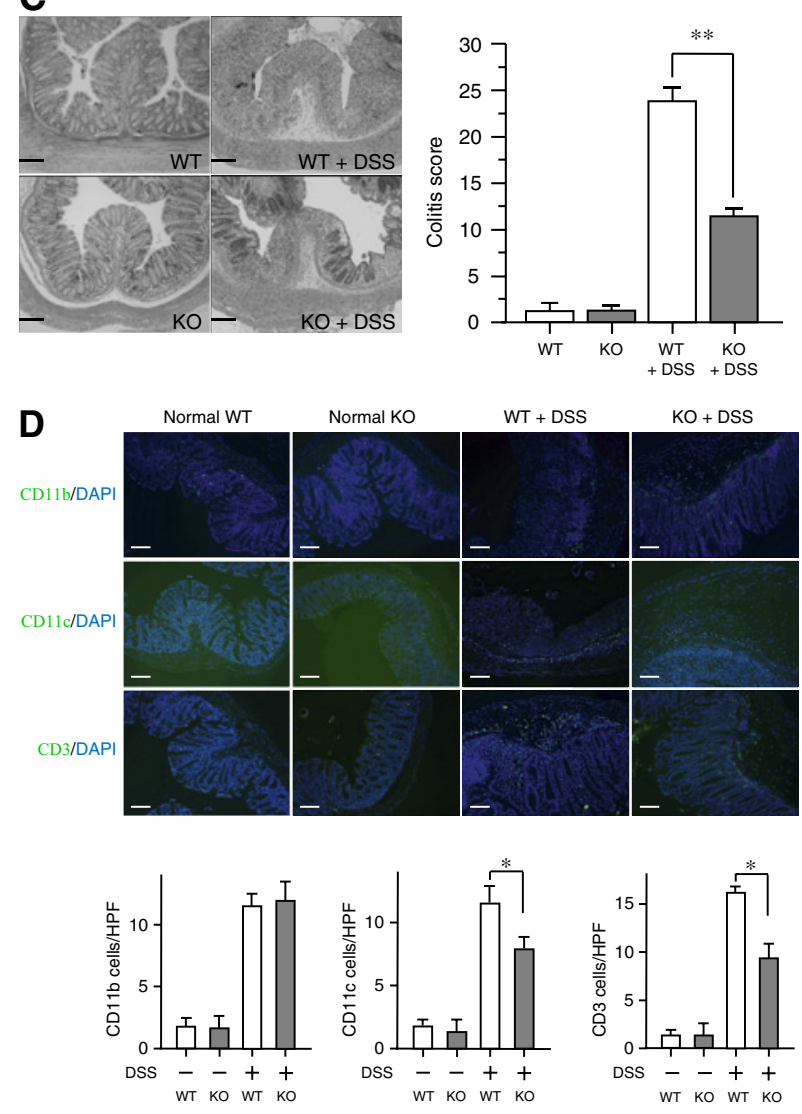

Figure 5 Activity of dextran sulfate sodium (DSS)-induced colitis is lower in SR-PSOX/CXCL16 knockout (KO) mice. (A) Serial change in body weight in SR-PSOX/CXCL16 KO and wild-type (WT) mice with or without 3\% DSS-induced colitis. Data are expressed as the percentage change from the starting body weight. (B) Representative image and colonic length in SR-PSOX/CXCL16 K0 and WT mice with or without 3\% DSS-induced colitis on day 8. (C) Representative histological findings and the scores of colonic inflammation of SR-PSOX/CXCL16 KO and WT mice with or without $3 \%$ DSS-induced colitis on day 8. Scale bars, $100 \mu \mathrm{m}$. (D) Colonic tissues of SR-PSOX/CXCL16 KO and WT mice with or without 3\% DSS-induced colitis were incubated with fluorescein isothiocyanate (FITC)-conjugated CD3, CD11b and CD11c, followed by nuclear counterstaining with 4',6-diamidino-2-phenylindole (DAPI). Scale bars, $100 \mu \mathrm{m}$. (E) Fluorescent in situ hybridization analysis was performed with colonic tissues of SR-PSOX/CXCL16 KO and WT mice with or without $3 \%$ DSS-induced colitis using eubacterial oligonucleotide probe EUB-338 (red), followed by DAPI (blue). Scale bars, $50 \mu \mathrm{m}$ (left two lanes) and $20 \mu \mathrm{m}$ (right lane). (F) Colonic macrophages from SR-PSOX/CXCL16 KO and WT mice were subjected to an ex vivo phagocytosis assay against bacteria. Scale bars, $25 \mu \mathrm{m}$. (G) MLN cells from SR-PSOX/CXCL16 KO and WT mice on days 0, 5 and 8 after administration of $3 \%$ DSS were cultured with immobilised anti-CD3 plus CD28. Supernatants were collected after $72 \mathrm{~h}$ and subjected to ELISA to measure the concentration of interferon $\gamma$ (IFN $\gamma$ ) and interleukin 17 (IL-17). $(A)-(D),(F)$ and $(G)$ The results are expressed as means \pm SEM $(n=10-12$ in each group). The statistical comparison was assessed by repeated measure analysis of variance followed by unpaired Student $t$ test $(A)$ and $(F)$. The statistical difference was determined by unpaired Student $t$ test $(B),(D)$ and $(G)$ or Mann-Whitney U test (C). ${ }^{*} p<0.05$ and ${ }^{* *} p<0.01$ between SR-PSOX/CXCL16 KO mice and WT mice with DSS-induced colitis. 
loss was significantly less in SR-PSOX/CXCL16 KO mice than in WT mice from 6 to 8 days after DSS administration (figure $5 \mathrm{~A}$ ). The colon was significantly longer in SR-PSOX/CXCL16 KO mice with DSS-induced colitis than in WT mice with DSSinduced colitis (figure 5B). The histological findings on day 8 after DSS administration in WT mice revealed severe epithelial destruction, remarkable infiltration of inflammatory cells with submucosal oedema, and crypt loss (figure 5C, right upper panel). In contrast, these findings were mild in SR-PSOX/ CXCL16 KO mice (figure 5C, right lower panel). The total colitis score was significantly lower in SR-PSOX/CXCL16 KO mice with DSS-induced colitis than in WT mice with DSS-induced colitis (figure 5C). Furthermore, fluorescent immunohistochemistry showed that the numbers of CD11c- and CD3-positive cells were significantly lower in colonic tissues of SR-PSOX/CXCL16 KO mice with DSS-induced colitis than in WT mice with DSSinduced colitis, despite no significant difference of the number of CD11b-positive cells between these two groups (figure 5D).

\section{SR-PSOX/CXCL16 is involved in bacterial invasion and phagocytosis of bacterial components in inflamed colonic tissues}

FISH with a universal oligonucleotide probe was performed to elucidate the difference in bacterial invasion of colonic tissues between SR-PSOX/CXCL16 KO and WT mice with/without colitis. FISH analysis showed that fewer bacteria invaded colonic tissues in SR-PSOX/CXCL16 KO mice with colitis compared with WT mice with colitis (figure 5E). Additionally, we investigated the phagocytic activity of colonic macrophages. Similar to the data with peritoneal macrophages, the fluorescence value was significantly lower from 60 to $180 \mathrm{~min}$ in SR-PSOX/CXCL16 KO colonic macrophages than in WT colonic macrophages (figure 5F).

\section{SR-PS0X/CXCL16 is related to the Th1 but not Th17 immune response in DSS-induced colitis}

Next, we measured cytokine production by MLN cells from both SR-PSOX/CXCL16 KO and WT mice with DSS-induced colitis. The production of IFN $\gamma$ on day 5 after DSS administration was significantly lower in SR-PSOX/CXCL16 KO mice than in WT mice (figure 5G). In contrast, the production of IL-17 did not differ significantly between SR-PSOX/CXCL16 $\mathrm{KO}$ and WT mice with DSS-induced colitis throughout the experiment (figure 5G).

\section{Administration of SR-PSOX/CXCL16 mAb attenuates experimental murine colitis}

To assess the neutralising effect of a mAb to SR-PSOX/CXCL16 in mice with colonic inflammation, we analysed two experimental murine colitis models: DSS-induced colitis as an epithelial injury model and TNBS-induced colitis as a Th1mediated colitis model. ${ }^{33}$ The body weight of mice with DSScolitis treated with control IgG decreased and reached the lowest level on day 9, and gradually increased thereafter, although complete recovery was not obtained even on day 14 . In contrast, in mice treated with SR-PSOX/CXCL16 mAb the body weight
Figure 6 Administration of SR-PSOX/ CXCL16 monoclonal antibody (mAb) attenuates dextran sulfate sodium (DSS)-induced colitis. A $500 \mu \mathrm{g}$ aliquot of SR-PSOX/CXCL16 mAb or an equal amount of control rat immunoglobulin (lgG) was administered to $\mathrm{C} 57 \mathrm{BL} / 6$ mice with $3 \%$ DSS-induced colitis by intraperitoneal injection once a day from day 1 to day 7. (A) Serial change in body weight in normal control mice (open circles), control IgG-treated mice with DSS-induced colitis (filled circles) and SR-PSOX/CXCL16 mAb-treated mice with DSS-induced colitis (grey circles). The data are expressed as the percentage change from the starting body weight. (B) Colonic length on day 8 and day 14 after administration of DSS. (C) Representative histological findings and the scores of colonic inflammation on day 8 and day 14 . Scale bars, $100 \mu \mathrm{m}$. The results are expressed as means \pm SEM $(n=12$ in each group). (A) The statistical comparison was assessed by repeated measure analysis of variance followed by unpaired Student t test. (B) and (C) The differences of colon length and colitis score between the groups were determined by unpaired Student $t$ test and Mann-Whitney U test, respectively. ${ }^{*} p<0.05$ and ${ }^{* *} p<0.01$ between SR-PSOX/CXCL16 mAbtreated and control IgG-treated mice with DSS-induced colitis.

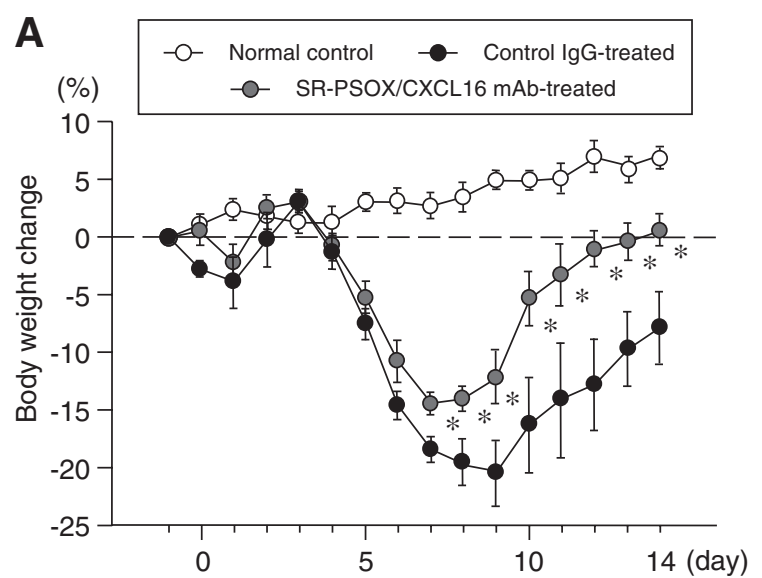

B
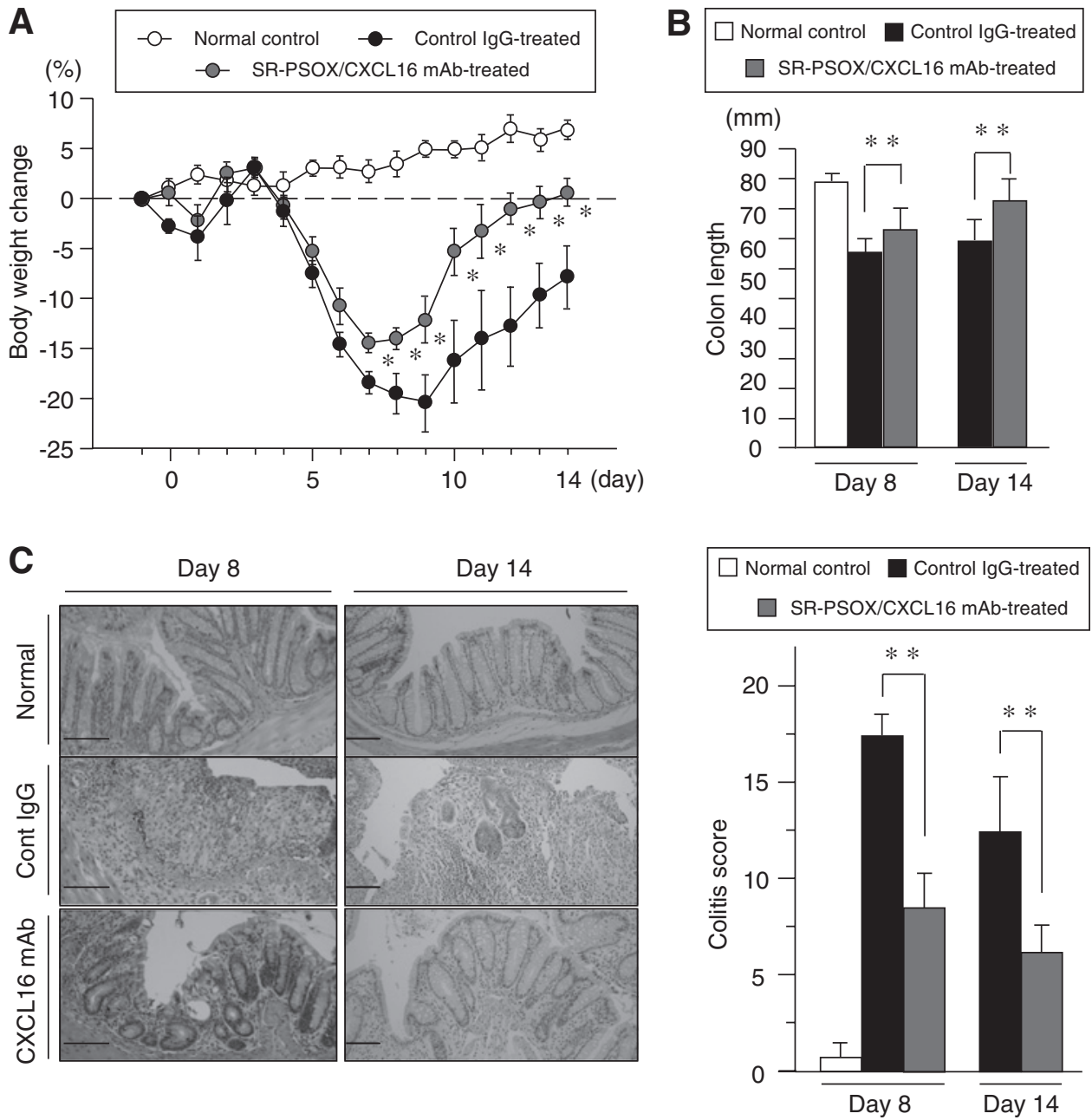
decreased to the lowest level on day 7 and recovered to a level similar to that before DSS administration on day 14 . The body weight of mice treated with SR-PSOX/CXCL16 mAb was significantly higher from day 7 to 14 than that of IgG-treated control mice (figure 6A). Furthermore, administration of SR-PSOX/CXCL16 mAb significantly attenuated the shortening of colonic length (figure $6 \mathrm{~B}$ ), and significantly reduced colonic damage and the colitis score of mice with DSS-induced colitis on both day 8 and day 14 (figure 6C).

In addition, in TNBS-induced colitis, administration of SR-PSOX/CXCL16 mAb significantly ameliorated the body weight change on day 4 (figure 7A). Histological findings showed severe epithelial destruction, marked infiltration of inflammatory cells with mucosal oedema and remarkable loss of cryptal cells in control IgG-treated mice. In contrast, these colonic inflammatory findings were attenuated in SR-PSOX/ CXCL16 mAb-treated mice. The colitis score was significantly lower in SR-PSOX/CXCL16 mAb-treated mice than in control IgG-treated mice (figure 7B). Furthermore, the overall survival rate of mice with TNBS-induced colitis treated with SR-PSOX/ CXCL16 mAb was significantly higher than that of control IgG-treated mice (78.7\% vs $38.9 \%$; $=0.04$; figure $7 \mathrm{C}$ ).

\section{DISCUSSION}

Recent genetic approaches for elucidating the pathogenesis of IBD revealed that abnormality of the genes related to the innate immune response by recognising and/or processing bacterial components is involved in the development of IBD. ${ }^{34-37}$ Kamada et al suggested that the abnormal response of intestinal macrophages to commensal bacteria results in chronic intestinal inflammation. ${ }^{4}$ Therefore, the control of the abnormal innate immune response of APCs to commensal bacteria is important in the treatment of IBD. Indeed, we showed that macrophagetargeting treatment ameliorates colonic inflammation in an experimental colitis model. ${ }^{5}$ Taken together, targeting molecules related to macrophages appears to be a promising approach for the treatment of IBD. SR-PSOX/CXCL16 may be one such candidate molecule, because it is mainly expressed in APCs.

First, we found that the serum level of SR-PSOX/CXCL16 was significantly higher in patients with active IBD as reported previously, ${ }^{38}$ and moreover that the level correlated with the disease activity in patients with IBD. Analysis of correlation between disease activity and SR-PSOX/CXCL16 or CRP suggests that the serum SR-PSOX/CXCL16 might be a suitable biomarker for evaluating disease activity of CD rather than UC.

Furthermore, we investigated the serum concentration and tissue expression of SR-PSOX/CXCL16 in mice with DSSinduced colitis. Similar to human IBD, the serum level of SR-PSOX/CXCL16 and its expression in colonic tissue was significantly higher in mice with DSS-induced colitis than in normal mice. In addition, SR-PSOX/CXCL16 was expressed mainly on CD11b-positive cells and markedly increased in the colonic mucosa of mice with DSS-induced colitis, although these cells were barely observed in the colonic mucosa under normal conditions. Previous reports have shown that several inflammatory cytokines including IFN $\gamma$, tumour necrosis factor $\alpha(\mathrm{TNF} \alpha)$ and IL-18 induce the expression of SR-PSOX/ CXCL16. ${ }^{39-41}$ Thus, increased concentration of various inflammatory cytokines in the inflamed colonic mucosa may contribute to enhanced expression of SR-PSOX/CXCL16 on macrophages.

Next, to evaluate the role of SR-PSOX/CXCL16 in both macrophage phagocytic activity and cytokine production, we examined phagocytosis and bacteria stimulated-cytokine
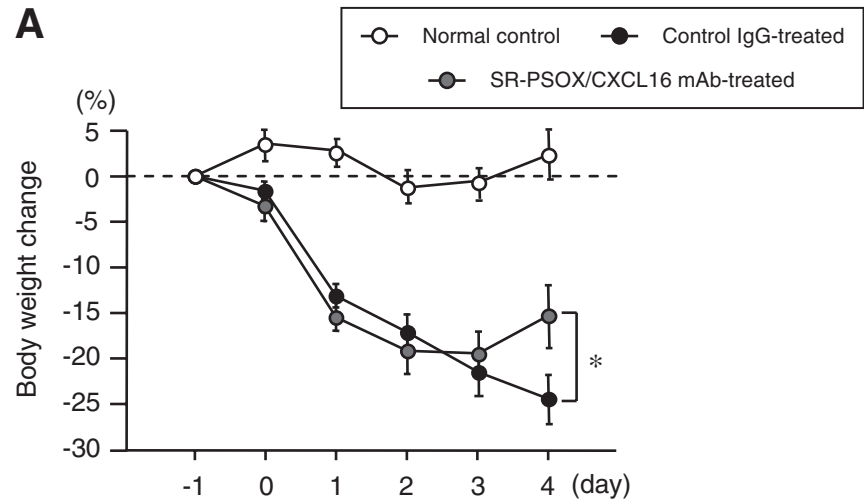

B
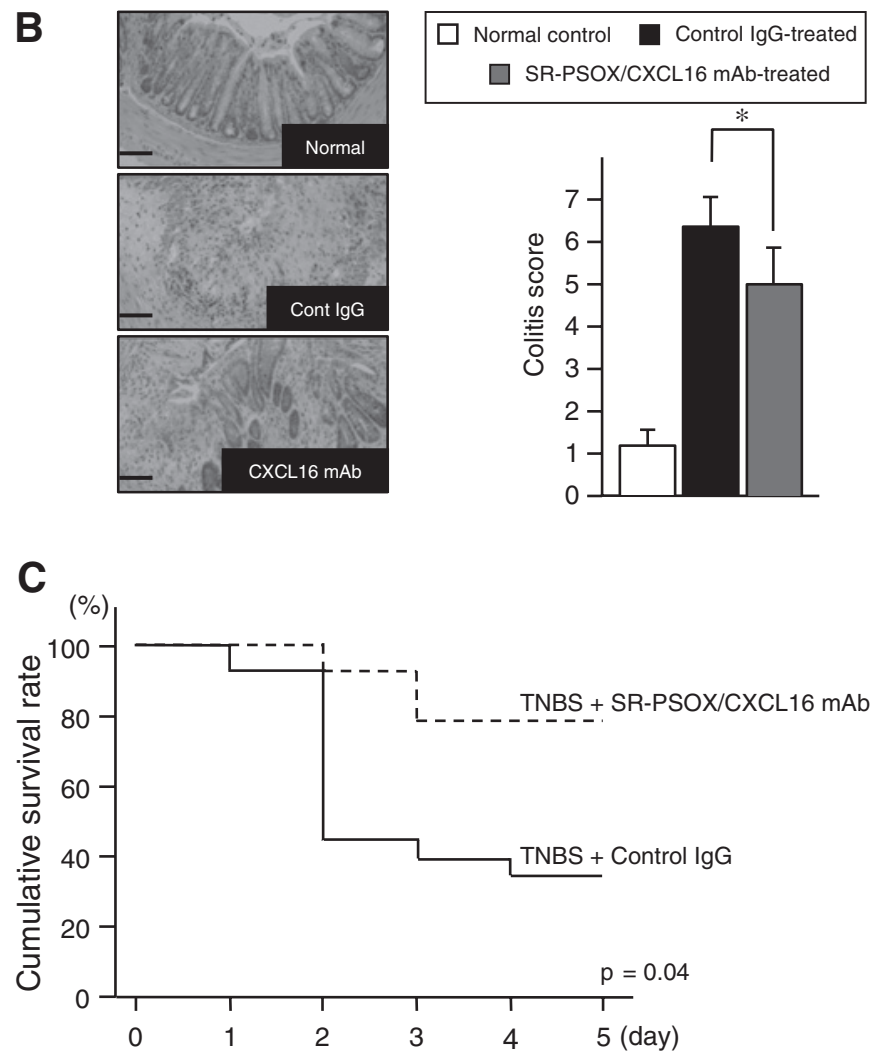

Figure 7 Administration of SR-PSOX/CXCL16 monoclonal antibody (mAb) attenuates trinitrobenzene sulfonic acid (TNBS)-induced colitis. A $500 \mu \mathrm{g}$ aliquot of SR-PSOX/CXCL16 mAb or an equal amount of control rat immunoglobulin $\mathrm{G}(\mathrm{IgG})$ was given to $\mathrm{SJL} / \mathrm{J}$ mice with TNBS-induced colitis by intraperitoneal injection once a day from day 1 to day 3. (A) Serial change in body weight in normal control mice (open circles), control IgG-treated mice with TNBS-induced colitis (filled circles) and SR-PSOX/ CXCL16 mAb-treated mice with TNBS-induced colitis (grey circles). The data are expressed as the percentage change from the starting body weight. (B) Representative histological findings and the scores of colonic inflammation on day 4 . Scale bars, $100 \mu \mathrm{m}$. The results are expressed as means $\pm S E M(n=8$ in each group). The difference of body weight change and colitis score between groups was assessed by repeated measure analysis of variance followed by unpaired Student $t$ test and Mann-Whitney U test, respectively. ${ }^{*} p<0.05$ between SR-PSOX/CXCL16 mAb-treated and control IgG-treated mice with TNBS-induced colitis. (C) Cumulative survival rate of mice with TNBS-colitis treated with SR-PSOX/ CXCL16 or control IgG was calculated by the Kaplan-Meier method, and survival curves were compared by log-rank test.

production in peritoneal macrophages from SR-PSOX/CXCL16 $\mathrm{KO}$ mice in vitro. Our data clearly demonstrated that both the phagocytic ability and IL-12 production of macrophages of 
SR-PSOX/CXCL16 KO mice was significantly impaired. Of note, LPS- and CBL-induced IL-12 production was significantly reduced in SR-PSOX/CXCL16 KO mice in the presence of IFN $\gamma$. This appears reasonable, because IFN $\gamma$ has been reported to enhance SR-PSOX/CXCL16 expression. ${ }^{39}$

The present study clearly showed that SR-PSOX/CXCL16 KO mice had reduced activity of DSS-induced colitis. Moreover, SR-PSOX/CXCL16 mAb ameliorated colitis in two different experimental models. These data indicate that SR-PSOX/ CXCL16 plays important roles in the development of colitis. The DSS-induced colitis model is characterised by direct epithelial injury and subsequent activation of macrophages, ${ }^{33}$ and SR-PSOX/CXCL16 is reported to be involved in DSS-induced IL-1 $\beta$ production by macrophages. ${ }^{42}$ Therefore, the DSS-induced colitis model is suitable for investigating the interaction between luminal bacteria and macrophages expressing SR-PSOX/ CXCL16. In our current study, SR-PSOX/CXCL16 was expressed predominantly on CD11b-positive cells at subepithelial sites of the inflamed colonic mucosa. In addition, we found that bacterial invasion of the lamina propria in the colitic mucosa was reduced in SR-PSOX/CXCL16 KO mice. SR-PSOX/CXCL16 has been reported to act as a scavenger receptor that mediates adhesion and phagocytosis of bacteria by APCs. ${ }^{14}$ In this connection, we demonstrated here that both peritoneal and intestinal macrophages of SR-PSOX/CXCL16 KO mice had reduced ability to phagocytose bacterial antigens. Taken together, our data suggest that SR-PSOX/CXCL16 exerts its colitogenic action at least in part by promoting bacterial uptake into macrophages in the colonic mucosa.

In this study, SR-PSOX/CXCL16 mAb also ameliorated TNBS-induced colitis, a Th1-mediated colitis model. An interesting finding in this study is that SR-PSOX/CXCL16 KO macrophages had an impaired ability to produce IL-12 in response to not only LPS but also commensal bacterial antigens, although their production of IL-6 was unaffected. Moreover, we observed that MLN cells from SR-PSOX/CXCL16 KO mice with DSS-induced colitis showed reduced production of IFN $\gamma$ but not of IL-17. Because IL-6 is essential for the induction of Th17 cells, the lack of difference in IL-6 production by macrophages or IL-17 production by MLN cells between SR-PSOX/CXCL16 KO and WT mice suggests that SR-PSOX/CXCL16 is not involved in the Th17-mediated immune response. Taken together, our data indicate that SR-PSOX/CXCL16 plays a colitogenic role by enhancing the Th1 immune response. Of note, IL-17A had a protective role in the CD45RB $B^{\mathrm{hi}}$ transfer model of colitis and suppressed the induction of T-bet in maturing Th1 cells. ${ }^{43}$ Thus, targeting SR-PSOX/CXCL16 seems to be an ideal treatment for preventing Th1-mediated colitis, without affecting the IL-17-mediated immune response.

In conclusion, our present data clearly demonstrated that SR-PSOX/CXCL16 plays a critical role in the development of colonic inflammation probably by both activating uptake of commensal bacteria and enhancing the Th1 immune response. SR-PSOX/CXCL16 may be a therapeutic target for patients with IBD.

Funding This work was supported by a Grant-in-Aid for Scientific Research (C) from the Ministry of Culture and Science of Japan (grant 18590677), the Kato Memorial Trust for Nambyo Research, the Shimizu Foundation for the Promotion of Immunology Research and the Japan Foundation for Applied Enzymology to HN, Grant-in-Aids for Scientific Research (16017240, 16017249, 17013051, 17659212 and 18012029) from the Ministry of Education, Culture, Sports, Science, and Technology of Japan, Grant-in-Aid for Scientific Research (15209024 and 18209027) from JSPS and Grant-in-Aid for Research on Measures for Intractable Diseases, and Research on Advanced Medical Technology (nano005) from the Ministry of Health, Labor, and Welfare, Japan to TC.

\section{Competing interests None.}

Patient consent Obtained.

Ethics approval This study was conducted with the approval of the Kyoto University Hospital Ethics Committee.

Provenance and peer review Not commissioned; externally peer reviewed.

\section{REFERENCES}

1. Podolsky DK. Inflammatory bowel disease. N Engl J Med 2002;347:417-29.

2. Cho $\mathbf{J H}$. The genetics and immunopathogenesis of inflammatory bowel disease. Nat Rev Immunol 2008;8:458-66.

3. Shih DQ, Targan SR, McGovern D. Recent advances in IBD pathogenesis: genetics and immunobiology. Curr Gastroenterol Rep 2008;10:568-75.

4. Kamada N, Hisamatsu T, Okamoto S, et al. Abnormally differentiated subsets of intestinal macrophage play a key role in Th1-dominant chronic colitis through excess production of IL-12 and IL-23 in response to bacteria. J Immunol 2005;175:6900-8.

5. Nakase H, Okazaki K, Tabata Y, et al. Development of an oral drug delivery system targeting immune-regulating cells in experimental inflammatory bowel disease: a new therapeutic strategy. J Pharmacol Exp Ther 2000;292:15-21.

6. Zlotnik A, Yoshie 0. Chemokines: a new classification system and their role in immunity. Immunity 2000;12:121-7.

7. Sallusto F, Mackay CR. Chemoattractants and their receptors in homeostasis and inflammation. Curr Opin Immunol 2004;16:724-31.

8. Bromley SK, Mempel TR, Luster AD. Orchestrating the orchestrators: chemokines in control of T cell traffic. Nat Immunol 2008; 9:970-80.

9. Zimmerman NP, Vongsa RA, Wendt MK, et al. Chemokines and chemokine receptors in mucosal homeostasis at the intestinal epithelial barrier in inflammatory bowel disease. Inflamm Bowel Dis 2008;14:1000-11.

10. Gijsbers K, Geboes K, Van Damme J. Chemokines in gastrointestinal disorders. Curr Drug Targets 2006; 7:47-64.

11. Shimaoka T, Kume N, Minami M, et al. Molecular cloning of a novel scavenger receptor for oxidized low density lipoprotein, SR-PSOX, on macrophages. J Biol Chem 2000;275:40663-6.

12. Matloubian M, David A, Engel S, et al. A transmembrane CXC chemokine is a ligand for HIV-coreceptor Bonzo. Nat Immunol 2000;1:298-304.

13. Wilbanks A, Zondlo SC, Murphy K, et al. Expression cloning of the STRL33/BONZO/ TYMSTR ligand reveals elements of CC, CXC, and CX3C chemokines. J Immunol 2001; 166:5145-54.

14. Shimaoka T, Nakayama T, Kume N, et al. Cutting edge: SR-PSOX/CXC chemokine ligand 16 mediates bacterial phagocytosis by APCs through its chemokine domain. $\mathrm{J}$ Immunol 2003;171:1647-51.

15. Yamauchi R, Tanaka M, Kume N, et al. Upregulation of SR-PSOX/CXCL16 and recruitment of $\mathrm{CD} 8+\mathrm{T}$ cells in cardiac valves during inflammatory valvular heart disease. Arterioscler Thromb Vasc Biol 2004;24:282-7.

16. Lehrke M, Millington SC, Lefterova M, et al. CXCL16 is a marker of inflammation, atherosclerosis, and acute coronary syndromes in humans. J Am Coll Cardiol 2007:49:442-9.

17. Wu T, Xie C, Wang HW, et al. Elevated urinary VCAM-1, P-selectin, soluble TNF receptor-1, and CXC chemokine ligand 16 in multiple murine lupus strains and human lupus nephritis. J Immunol 2007:179:7166-75.

18. Best WR, Becktel JM, Singleton JW, et al. Development of a Crohn's disease activity index. National Cooperative Crohn's Disease Study. Gastroenterology 1976;70:439-44.

19. Rachmilewitz D. Coated mesalazine (5-aminosalicylic acid) versus sulphasalazine in the treatment of active ulcerative colitis: a randomised trial. BMJ 1989;298:82-6.

20. Targan SR, Hanauer SB, van Deventer SJ, et al. A short-term study of chimeric monoclonal antibody CA2 to tumor necrosis factor alpha for Crohn's disease. Crohn's Disease cA2 Study Group. N Engl J Med 1997;337:1029-35.

21. Andus T, Klebl F, Rogler G, et al. Patients with refractory Crohn's disease or ulcerative colitis respond to dehydroepiandrosterone: a pilot study. Aliment Pharmacol Ther 2003:17:409-14.

22. Shimaoka T, Seino K, Kume N, et al. Critical role for CXC chemokine ligand 16 (SR-PSOX) in Th1 response mediated by NKT cells. J Immunol 2007;179:8172-9.

23. Cong $Y$, Brandwein SL, McCabe RP, et al. CD4 + T cells reactive to enteric bacterial antigens in spontaneously colitic C3H/HeJBir mice: increased Thelper cell type 1 response and ability to transfer disease. J Exp Med 1998;187:855-64.

24. Inoue $\mathbf{S}$, Nakase $\mathrm{H}$, Matsuura $\mathrm{M}$, et al. The effect of proteasome inhibitor MG 132 on experimental inflammatory bowel disease. Clin Exp Immunol 2009;156:172-82.

25. Neurath MF, Fuss I, Kelsall BL, et al. Antibodies to interleukin 12 abrogate established experimental colitis in mice. J Exp Med 1995;182:1281-90.

26. Shimaoka T, Nakayama T, Fukumoto N, et al. Cell surface-anchored SR-PSOX/CXC chemokine ligand 16 mediates firm adhesion of CXC chemokine receptor 6-expressing cells. J Leukoc Biol 2004;75:267-74.

27. Matsuura M, Okazaki K, Nishio A, et al. Therapeutic effects of rectal administration of basic fibroblast growth factor on experimental murine colitis. Gastroenterology 2005; 128:975-86.

28. Williams KL, Fuller $C R$, Dieleman $L A$, et al. Enhanced survival and mucosal repair after dextran sodium sulfate-induced colitis in transgenic mice that overexpress growth hormone. Gastroenterology 2001;120:925-37. 
29. Elson C0, Beagley KW, Sharmanov AT, et al. Hapten-induced model of murine inflammatory bowel disease: mucosa immune responses and protection by tolerance. $\mathrm{J}$ Immunol 1996;157:2174-85.

30. Sellon RK, Tonkonogy S, Schultz M, et al. Resident enteric bacteria are necessary for development of spontaneous colitis and immune system activation in interleukin-10-deficient mice. Infect Immun 1998;66:5224-31.

31. Mikami S, Nakase H, Yamamoto S, et al. Blockade of CXCL12/CXCR4 axis ameliorates murine experimental colitis. J Pharmacol Exp Ther 2008;327:383-92.

32. Hase K, Murakami T, Takatsu $\mathrm{H}$, et al. The membrane-bound chemokine CXCL16 expressed on follicle-associated epithelium and $\mathrm{M}$ cells mediates lympho-epithelial interaction in GALT. J Immunol 2006;176:43-51.

33. Sartor RB. Animal models of intestinal inflammation. In: Sartor RB, Sandborn WJ, eds. Kirsner's Inflammatory Bowel Disease. 6th edn. Edinburgh: Saunders, 2004:120-37.

34. Hugot JP, Chamaillard M, Zouali $\mathrm{H}$, et al. Association of NOD2 leucine-rich repeat variants with susceptibility to Crohn's disease. Nature 2001;411:599-603.

35. Ogura Y, Bonen DK, Inohara N, et al. A frameshift mutation in NOD2 associated with susceptibility to Crohn's disease. Nature 2001:411:603-6.

36. Hampe J, Franke A, Rosenstiel P, et al. A genome-wide association scan of nonsynonymous SNPs identifies a susceptibility variant for Crohn's disease in ATG16L1. Nat Genet 2007;39:207-11.
37. Parkes M, Barrett JC, Prescott NJ, et al. Sequence variants in the autophagy gene IRGM and multiple other replicating loci contribute to Crohn's disease susceptibility Nat Genet 2007;39:830-2.

38. Lehrke M, Konrad A, Schachinger $\mathbf{V}$, et al. CXCL16 is a surrogate marker of inflammatory bowel disease. Scand J Gastroenterol 2008;43:283-8.

39. Wuttge DM, Zhou X Sheikine $Y$, et al. CXCL16/SR-PSOX is an interferon- $\gamma$ regulated chemokine and scavenger receptor expressed in atherosclerotic lesions. Arterioscler Thromb Vasc Biol 2004;24:750-5

40. Abel S, Hundhausen C, Mentlein R, et al. The transmembrane CXC-chemokine ligand 16 is induced by IFN- $\gamma$ and TNF- $\alpha$ and shed by the activity of the disintegrin-like metalloproteinase ADAM10. J Immunol 2004;172:6362-72.

41. Chandrasekar B, Mummidi S, Valente AJ, et al. The pro-atherogenic cytokine interleukin-18 induces CXCL16 expression in rat aortic smooth muscle cells via MyD88, interleukin-1 receptor-associated kinase, tumor necrosis factor receptorassociated factor 6, c-Src, phosphatidylinositol 3-kinase, Akt, c-Jun N-terminal kinase, and activator protein-1 signaling. J Biol Chem 2005;280:26263-77.

42. Kwon KH, Ohigashi H, Murakami A. Dextran sulfate sodium enhances interleukinbeta release via activation of p38 MAPK and ERK1/2 pathways in murine peritoneal macrophages. Life Sci 2007;81:362-71.

43. O'Connor W Jr, Kamanaka M, Booth CJ, et al. A protective function for interleukin 17A in T cell-mediated intestinal inflammation. Nat Immunol 2009;10:603-9.

\section{Left lower quadrant abdominal pain caused by an IUCD}

\section{CLINICAL PRESENTATION}

A previously healthy 42-year-old woman presented with mild left lower quadrant abdominal pain. There was no relevant medical or family history except she had a T-shaped copper intrauterine contraceptive device (IUCD) inserted 10 years previously. The remainder of her obstetric history was nonspecific and included one normal vaginal delivery. Physical examination and laboratory findings at the time of presentation were unremarkable.

Plain radiographs of the abdomen identified the IUCD in the pelvic cavity (figure 1); however, the IUCD was not detected during gynaecological ultrasonography. Further abdominal CT

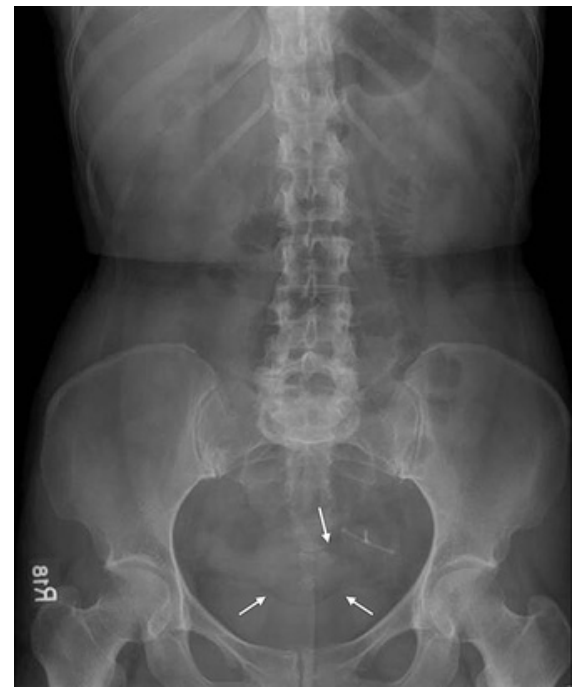

Figure 1 Plain abdominal radiograph showed the T-shaped intrauterine contraceptive device (IUCD) in the left pelvic cavity. The surrounding fat planes of the uterus were identified (arrows) and the device appeared separate from the fat planes.

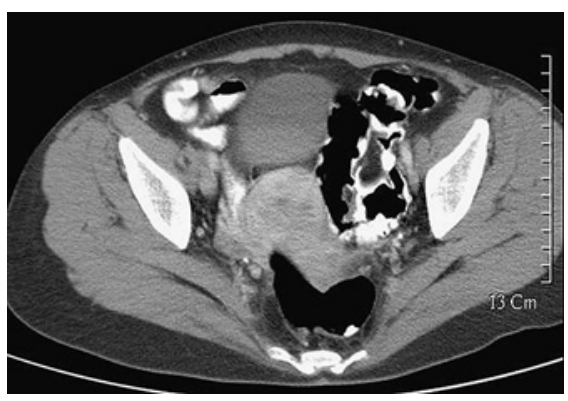

Figure 2 Contrast-enhanced CT scan using the soft tissue window setting did not identify any definite focal lesions.

scanning did not reveal any definite focal lesions and the IUCD was not identified (figure 2).

\section{QUESTION}

What is your diagnosis?

What additional tests are indicated and how should the patient be managed?

See page 1562 for the answer

\section{Huan-Lun Hsu, ${ }^{1}$ Chin-Chen Chang, ${ }^{2}$ Jin-Tung Liang, ${ }^{3}$ Kao-Lang Liu ${ }^{2}$}

${ }^{1}$ Department of Internal Medicine, Far Eastern Memorial Hospital, National Taiwan University Hospital and National Taiwan University College of Medicine, Taipei, Taiwan; ${ }^{2}$ Departments of Medical Imaging, National Taiwan University Hospital and National Taiwan University College of Medicine, Taipei, Taiwan; ${ }^{3}$ Department of Surgery, National Taiwan University Hospital and National Taiwan University College of Medicine, Taipei, Taiwan

Correspondence to Dr Kao-Lang Liu, Department of Medical Imaging, National Taiwan University Hospital, No. 7, Chung-Shan South Road, Taipei, Taiwan; |k|@ntu.edu.tw

Competing interests None.

Patient consent Obtained

Provenance and peer review Not commissioned; externally peer reviewed.

Published Online First 4 March 2011

Gut 2011;60:1505. doi:10.1136/gut.2010.209486 


\section{SR-PSOX/CXCL16 plays a critical role in the progression of colonic inflammation}

Norimitsu Uza, Hiroshi Nakase, Shuji Yamamoto, et al.

Gut 2011 60: 1494-1505 originally published online April 6, 2011

doi: 10.1136/gut.2010.221879

Updated information and services can be found at:

http://gut.bmj.com/content/60/11/1494.full.html

\section{These include:}

Data Supplement

"online only data"

http://gut.bmj.com/content/suppl/2011/10/12/gut.2010.221879.DC1.html

References This article cites 42 articles, 20 of which can be accessed free at: http://gut.bmj.com/content/60/11/1494.full.html\#ref-list-1

Email alerting Receive free email alerts when new articles cite this article. Sign up in service the box at the top right corner of the online article.

Notes

To request permissions go to:

http://group.bmj.com/group/rights-licensing/permissions

To order reprints go to:

http://journals.bmj.com/cgi/reprintform

To subscribe to BMJ go to:

http://group.bmj.com/subscribe/ 